\title{
CONTINUOUS MONITORING OF OUT-OF-HOSPITAL CARDIAC ARREST IN MUNICIPALITY SOMBOR - EURECA_SRBIJA
}

Snežana Holcer Vukelić ${ }^{1}$, Ivan Pešić ${ }^{1}$

\section{SAŽETAK}

CILJ:

Praćenje epidemiologije vanbolničkog srčanog zastoja na teritoriji opštine Sombor u vremenskom periodu 01. januar 2016 - 01. jun 2017. sa ciljem utvrđivanja kvaliteta zbrinjavanja VBSZ.

\section{METODOLOCIUA:}

U metodologiji rada su obrađivani prikupljeni podaci iz prospektivne, opservacionog trijala Evropskog Resuscitacionog Saveta Srbije koji je pod brojem NCTO2236819 registrovan u bazi trijala i odbren od zdravstvenih autoriteta u SAD. Ovaj program je organizovao Resuscitacioni Savet Srbije a na osnovu ovlaščenja Evropskog Resuscitacionog Saveta a uz podršku Sekcije urgentne medicine-SLD. Podaci su unešeni od strane glavnog istraživača u jedinstvenu bazu podataka putem onlajn unosa i aplikacije prilagođene za rad na mobilnom telefonu postavljene na adresi www.eureca.rs

\section{REZULTATI:}

Služba hitne medicinske pomoći Sombor pokriva teritoriju od 85.900 stanovnika. U posmatranom periodu na lekarske ekipe Službe hitne medicinske pomoći (SHMP) su potvrdile 119 (138,5/100.000) vanbolničkih srčanih zastoja. Kardiopulmonalna resuscitacija (KPR) je započeta kod 94 (109,4/100.000) pacijenata. Polna distribucija ukazuje na 58 VBSZ kod muškaraca i 36 kod žena. Najčešći etiološki uzrok VBSZ je kardiološki 61 (71/100.000) pacijenata. Prebivalište je najčešče mesto nastanka VBSZ 69 sa incidencom 80,3/100.000). Svedok je bio prisutan kod 61 VBSZ (71/100.000), a svedok- laik je KPR započeo 19 (22/100.000)puta do dolaska SHMP. Telefonski vođen KPR od strane dispečera 14 (16,2/100.000) puta. Inicijalni šokabilan ritam (vetrikularna tahikardija bez pusa VT /ventrikularna fibrilacija VF) je imalo 30 $(34,9 / 100.000)$ pacijenata, ne šokabilan ritam (asistolija/PEA) je imalo 64 (74,5/100.000) pacijenata. Spoljašnji automatski defibrilator (AED) se ni jednom nije primenio. Povratak spontane cirkulacije (ROSC) je postignut kod 51 (59,3/100.000). Posmatrajući cirkadijalni ritam postignutog ROSC-a, uočavamo da je povratak spontane cirkulacije najčešće postignut u vremenskom periodu 6-14 časova. Do otpusta preživelo $6(6,9 / 100.000)$ pacijenta sa vanbolničkim srčanim zastojem, a nakon 30 dana 4 (4,6/100.000)

\section{ZAKLUČAK:}

Posmatranjem epidemioloških podataka vanbolničkog srčanog zastoja, uočavamo promene u kvalitetu zbrinjavanja pacijenata koji su doživeli srčani zastoj. Analize ukazuju da je veća incidenca gotovo svih parametara koji su obuhvaćeni studijom u odnosu na raniji period. Dalja opservacija će nam omogućiti da sagledamo koji su to sve faktori koji su doprineli poboljšanju rezultata kako bi se održao odn. nastavio pozitivan trend.

\author{
ABSTRACT

\section{AlMS:} \\ Epidemiological follow up of out-of-hospital cardiac arrest (OHCA) in Mu- \\ nicipality Sombor in period of $1^{\text {st }}$ of January 2016 until $1^{\text {st }}$ of June 2017. \\ With focus on OHCA quality management.
}

\section{METODOLOGIJA:}

The project EuReCa is a part of a metacentric, observational, prospective study of an observational trail of the European Resuscitation Council registered Clinical Trial NCT02236819 and approved by the US healthcare authorities. The EuReCa_Srbija project is conducted by the Serbian Resuscitation Council, based on collaboration with the European Resuscitation Council with support of the Section of Emergency Medicine - Serbian Physicians Society. The data's from the Serbian cardiac arrest registry has been collected and analyzed via www.eureca.rs application.

\section{RESULTS:}

Emergency medical service (EMS) in Sombor covers 85.900 citizens. In observed period 119 (138,5/100.000) OHCA's were registered. Cardiopulmonary resuscitation (CPR) was applied $94(109,4 / 100.000)$ cases. Gender distribution shows that 58 OHCA occurred in male and 36 in female population. The most common etiological cause of OHCA had cardiac background in $61(71 / 100.000)$ patinets. Home is the most common place where OHCA occurred in 69 cases with incidence 80,3/100.000). Witness was present 61 OHCA (71/100.000), and lay-person CPR was performed in $19(22 / 100.000)$ patients until the arrival of the EMS. TeleCPR by the dispatcher was registered in $14(16,2 / 100.000)$ cases. The initial shockable rhythm (pulseless ventricular tachycardia pVT /ventricular fibrillation VF) was observed in $30(34,9 / 100.000)$ patients, and nonshockable rhythm (asistoly/ PEA) in 64 (74,5/100.000). Automated external defibrillator (AED) was never used. Return of spontaneous circulation (ROSC) was achieved in 51 (59,3/100.000) cases. At circadian ROSC distributionROSC was most commonly achieved in period between 6-14 hours. Hospital OHCA discharge survival was $6(6,9 / 100.000)$, and the 30 -days survival rate is $4(4,6 / 100.000)$.

\section{CONCLUSION:}

By observing the epidemiological parameters of the OHCA, quality management related points were highlighted. The analyzed data's points to the fact that there is a higher incidence of almost all parameters included in the study protocol compared to previous period. Further observation and analysis will contribute to overall deeper insight of each observed segment that contributed to better and improved outcome with aim to continue the trend of positivity.

\section{USTANOVA}

${ }^{1}$ Dom zdravlja Sombor

\section{AUTOR ZA}

\section{KORESPODENCIUU.}

Snežana Holcer Vukelić

Dom zdravlja Sombor

zokiswim@gmail.com

\section{KLUUČNE REČl:}

vanbolnički srčani zastoj, KPR, Služba hitne pomoći

\section{KEY WORDS:}

out-of-hospital cardiac arrest, CPR emergency medical service
DATUM PRIJEMA RADA

10. jul 2018. DATUM PRIHUATANIA RADA 31. jul 2018. datum Objayluivanja

24. septembar 2018 


\section{UVOD:}

Služba hitne medicinske pomoći Sombor se priključuje programu EuReCa One 2014. godine. Od tada naša ustanova u kontinuitetu prikuplja podatke o vanbolničkom srčanom zastoju. Prvi rezultati epidemiologije VBSZ u Srbiji se objavljuju od 2015. godine i na taj način se omogućuje praćenje trenda i uporedna analiza svih centara koji učestvuju u programu. Jednoipogodišnji period koji je obuhvaćen ovom analizom je najduži period posmatranja koji će dati jasniju sliku zbrinjavanja ove pojave kao i rada naše službe.

\section{CIL:}

Praćenje epidemiologije vanbolničkog srčanog zastoja na teritoriji opštine Sombor u vremenskom periodu 01. januar 2016 - 01. jun 2017. sa ciljem utvrđivanja kvaliteta zbrinjavanja VBSZ.

\section{METODOLOGIJA:}

U metodologiji rada su obrađivani prikupljeni podaci iz prospektivne, opservacionog trijala Evropskog Resuscitacionog Saveta Srbije koji je pod brojem NCT02236819 registrovan u bazi trijala i odbren od zdravstvenih autoriteta u SAD. Ovaj program je organizovao Resuscitacioni Savet Srbije a na osnovu ovlašćenja Evropskog Resuscitacionog Saveta a uz podršku Sekcije urgentne medicine-SLD. Metodologijom studije je ustanovljen način šifriranja podataka te čuvanja integriteta ličnosti i poverljivosti podataka pacijenata koji su obuhvaćeni studijom. Podaci su unešeni od strane glavnog istraživača u jedinstvenu bazu podataka putem onlajn unosa i aplikacije prilagođene za rad na mobilnom telefonu postavljene na adresi www.eureca.rs

\section{REZULTATH}

Služba hitne medicinske pomoći Sombor pokriva teritoriju od 85.900 stanovnika. U posmatranom periodu na lekarske ekipe Službe hitne medicinske pomoći (SHMP) su potvrdile 119 (138,5/100.000) vanbolničkih srčanih zastoja. U tabeli 1. je modifikovani prikaz Utstain protokola vanbolničkog srčanog zastoja u Somboru. Kardiopulmonalna resuscitacija (KPR) je započeta kod 94 (109,4/100.000) pacijenata. Tabela 2. sadrži incidencu parametara posmatranih studijom. Prema starosnoj strukturi se uočava distribucija od 1 do 88 godina. Polna distribucija ukazuje na 58 VBSZ kod muškaraca i 36 kod žena. Najčešči etiološki uzrok VBSZ je kardiološki 61 (71/100.000) pacijenata, respiratorni 3 (3,4/100.000), ne kardiološki 7 (8,1/100.000) dok je nepoznati (pretpostavljeni kardiološki) zabeležen kod 21 (24,4/100.000) pacijenta. Prebivalište je najčešće mesto nastanka VBSZ 69 (80,3/100.000), ulica 5 (5,8/100.000), u javna ustanova $4(4,6 / 100.000)$ na radnom mestu 3 (3,4/100.000). Svedok je bio prisutan kod 61 VBSZ (71/100.000), a svedok- laik je KPR započeo 19 (22/100.000)puta do dolaska SHMP. Telefonski vođen KPR od strane dispečera 14 (16,2/100.000) puta. Inicijalni šokabilan ritam (vetrikularna tahikardija bez pusa VT /ventrikularna fibrilacija VF) je imalo 30 (34,9/100.000) pacijenata, ne šokabilan ritam (asistolija/PEA) je imalo 64 (74,5/100.000) pacijenata. Ukupno je DC šok isporučen kod 43 (50/100.000) pacijenta. Spoljašnji automatski defibrilator (AED) se ni jednom nije primenio. Povratak spontane cirkulacije (ROSC) je postignut kod 51 (59,3/100.000). Posmatrajući cirkadijalni ritam postignutog ROSC-a, uočavamo da je povratak spontane cirkulacije najčešće postignut u vremenskom periodu 6-14 časova (tabela 3). Do otpusta preživelo $6(6,9 / 100.000)$ pacijenta sa vanbolničkim srčanim zastojem, a nakon 30 dana 4 $(4,6 / 100.000)$.

\section{DISKUSIJA:}

Incidenca vanbolničkog srčanog zastoja na teritoriji opštine Sombor u posmatranom periodu je približno sličan incidenci zabeleženoj 2014. godine ${ }^{1}$. Približno slična incidenca VBSZ je registrovana tokom EuReCa One studije u Mađarskoj (118/100.000), u Italiji (116/100.000) i Nemačkoj (122/100.000)2. Incidenca započetih kardiopulmonalnih resuscitacija se znatnoj meri povećala (109 vs. 75) u odnosu na početnu godinu posmatranja incidence VBSZ 1. Posmatrajući doba dana u našoj analizi, KPR je u najvećem procentu započet tokom dana, u periodu od 6 do 20 časova, odn. ređe se javlja tokom noći, što je zabeleženo i u ranijim analizama ${ }^{3,4}$. Vanbolnički srčani zastoj se češće javlja kod osoba muškog pola ${ }^{5}$, prebivalište je najčešće mesto zadesa kako prema našoj tako i u drugim analizama epidemiologije vanbolničkog srčanog zastoja ${ }^{6,7}$. U posmatranom periodu, visoka incidenca prebivališta kao mesta VBSZ (80/100.000) je u korelaciji sa visokom incidencom prisutnog svedoka (71/100.000). Trend započinjanja mera kardiopulmonalne resuscitacije je gotovo dvostruko viši u poređenju sa drugim gradovima, kao i telefonski asistiran KPR od strane dispečera ${ }^{8}$. Kontinualno praćenje pojave srčanog zastoja dovele su do vidljivih rezultata i veće motivisanosti kako dispečera da insistiraju na ranom započinjanju kompresija grudnog koša i primeni ventilacija od strane laika tako i na saradnji građana. Sve to je doprinelo da je incidenca zabeleženog inicijalnog šokabilnog ritma ulazi u opseg evropskih rezultata 


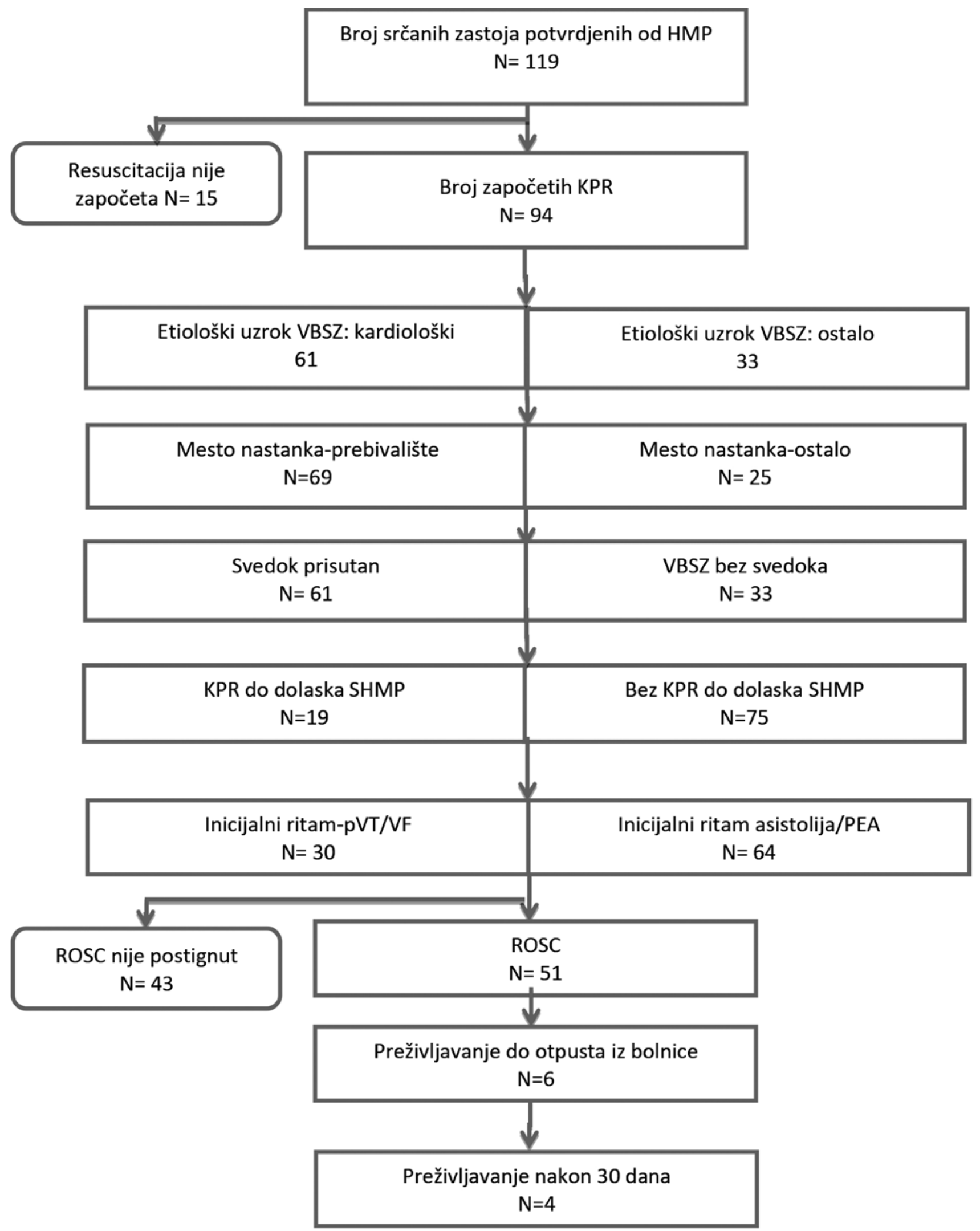


gde se incidenca kreće od 4 do 50 na 100.000 stanovni$\mathrm{ka}^{2}$. Četrnaest pacijenata u našoj studiji je imalo inicijalno ne šokabilni ritam te su konvertovani u ritam za isporuku DC šoka. Studija sprovedena u Japanu, ukazuje da je bolji neurološki odgovor i jednomesečno preživljavanje kod pacijenata kod kojih je primenjen DC šok unutar 20 minuta od započinjanja mera resuscitacije a koji su inicijalno imali ne šokabilan ritam ${ }^{9}$. Potrebna su dalje analize koji bi se mogle primeniti i ustanoviti preživljavanje ovih pacijenata na našem uzorku. Incidenca uspostavljene spontane cirkulacije je znatno viša od incidence zabeležene u analizama u našoj zemlji 6,8,10,11. Posmatrajući cirkadijalni ritam iz naše analize, najveća učestalost pojave vanbolničkog srčanog zastoja, prisutnost svedoka, započinjanja KPR kao i uspostavljanja spontane cirkulacije je zabeležena u vremenskom periodu (6-14 časova). $U$ istom periodu je i veći procenat preživljavanja pacijenata koji su u posmatranom vremenskom periodu doživeli VBSZ. Objavljena studija ${ }^{12}$ ukazuje na značajno veće preživljavanje pacijenata 30 dana nakon otpusta ukoliko su doživeli srčani zastoj tokom dana u poređenju sa pacijentima koji su imali VBSZ tokom noći.

\section{ZAKLUČAK:}

Posmatranjem epidemioloških podataka vanbolničkog srčanog zastoja, uočavamo promene u kvalitetu zbrinjavanja pacijenata koji su doživeli srčani zastoj. Analize ukazuju da je veća incidenca gotovo svih parametara koji su obuhvaćeni studijom u odnosu na raniji period. Dalja opservacija će nam omogućiti da sagledamo koji su to sve faktori koji su doprineli poboljšanju rezultata kako bi se održao odn. nastavio pozitivan trend.

Tabela 2. Prikaz incidence VBSZ za period 1. januar 2016- 1.jun 2017.

\begin{tabular}{|l|l|}
\hline VBSZ- Sombor & $2016-2017(\mathrm{n} / 100.000)$ \\
\hline Broj započetih resuscitacija & $94(109,4)$ \\
\hline Etiologija - kardiološka & $61(71)$ \\
\hline Mesto nastanka SZ-prebivalište & $69(80,3)$ \\
\hline Svedok prisutan & $61(71)$ \\
\hline Telefonski vođen KPR & $19(2,2)$ \\
\hline Inicijalni ritam za isporuku šoka & $30(34,9)$ \\
\hline ROSC & $51(59,3)$ \\
\hline Preživljavanje do otpusta & $6(6,9)$ \\
\hline Preživljavanje nakon 30d od otpusta & $4(4,6)$ \\
\hline
\end{tabular}

Tabela 3. Cirkadijalni ritam vanbolničkog srčanog zastoja

\begin{tabular}{|l|l|l|l|l|l|}
\hline & $\begin{array}{l}\text { KPR } \\
(\%)\end{array}$ & $\begin{array}{l}\text { SVEDOK } \\
(\%)\end{array}$ & $\begin{array}{l}\text { SVEDOK } \\
\text { KPR (\%) }\end{array}$ & ROSC (\%) & $\begin{array}{l}\text { PREŽIVLJA- } \\
\text { VANJE na- } \\
\text { kon 30d (\%) }\end{array}$ \\
\hline 0-6 časova & $\begin{array}{l}12 \\
(13)\end{array}$ & $7(11)$ & $2(10)$ & $4(8)$ & 0 \\
\hline 6-14 časova & $\begin{array}{l}39 \\
(41)\end{array}$ & $26(4)$ & $8(42)$ & $25(50)$ & $2(50)$ \\
\hline $14-20$ časova & $\begin{array}{l}31 \\
(33)\end{array}$ & $20(33)$ & $6(32)$ & $16(31)$ & $1(25)$ \\
\hline 20-24 časova & $\begin{array}{l}12 \\
(13)\end{array}$ & $8(13)$ & $3(16)$ & $6(11)$ & $1(25)$ \\
\hline UKUPNO & $\begin{array}{l}94 \\
(100)\end{array}$ & $61(100)$ & $19(100)$ & $51(100)$ & $4(100)$ \\
\hline
\end{tabular}

\section{Lista skraćenica}

\begin{tabular}{l|l|}
\hline EuReCa & registar vanbolničkog srčanog zastoja \\
\hline VBSZ & vanbolnički srčani zastoj \\
\hline KPR & kardiopulmonalna resuscitacija \\
\hline tele KPR & telefonski asistirana kardiopulmonalna resuscitacija \\
\hline SHMP & Služba hitne medicinske pomoći \\
\hline pVT & ventrikularna tahikardija bez pulsa \\
\hline VF & ventrikularna fibrilacija \\
\hline PEA & električna aktivnost bez pulsa \\
\hline ROSC & povratak spontane cirkulacije \\
\hline vS & versus - naspram \\
\hline
\end{tabular}

\section{Konflikt interesa:}

Autor i koautori izjavljuju da nemaju konflikt interesa

\section{Zahualnost:}

Autori se zahvaljuju svim učesnicima na pomoći u prikupljanju podataka kao i Resuscitacionom Savetu Srbije.

\section{Finansijskka podrška:}

Studiju iz koje proističu podaci finansirao je Resuscitacioni savet Srbije iz sredstava članarine. Autori i koautori nemaju naknadu za učešće u studiji, niti za pisanje rada.

\section{LITERATURA}

1. Holcer V.S, Mitrović M, Pešić I. Eureca Serbia One 2014-istraživački centar Sombor. Rezultati istraživanja oktobar-decembar 2014. godine i prikaz na godišnjem nivou. ABC časopis urgentne medicine. 2015; XIV:3:60-64.

2. Gräsner J.T. et al. EuReCa ONE-27 Nations, ONE Europe, ONE Registry A prospective one month analysis of out-of-hospital cardiac arrest outcomes in 27 countries in Europe. Resuscitation 2016; 105 :188-195.

3. Beljić N. Tomić B. Cirkardijalni ritam i polna distibucija srčanog zastoja. ABC časopis urgentne medicine 2018;18:(2):16-21.

4. Yosuke Matsumura Y. Nakada T. Shinozaki K. et. al. Nighttime is associated with decreased survival and resuscitation efforts for out-of-hospital cardiac arrests: a prospective observational study. Crit Care. 2016; 20: 141. 
5. Jakšić H.K, Budimski M, Holcer V.S. Analiza epidemioloških podataka vanbolničkog srčanog zastoja kod žena u Vojvodini. Journal Resuscitatio Balcanica 2018; 9: 79-84.

6. Fišer Z. , Jakšić Horvat K., Vlajović S., Milić S. , Lazić A. ,Raffay V.; EURECA ONE 2014 SRBIJA; Medicina danas 2015;14(7-9):95-102

7. Budimski M, Jakšić H.K, Stojković M.M. Eureca Srbija 2015-2016 dvogodišnja analiza. Journal Resuscitatio Balcanica. 2017; 6:18-21.

8. Stojković M.M. Gavrilović N. Jakšić HK. EuReCa_Srbija Subotica 2015-2016. - Da li jačanje sistema dovodi do rezultata? Journal Resuscitatio Balcanica $2017 ; 7$ : 33-36.
9. GotoY., Maeda T., Goto N.Y. Prognostic implications of conversion from nonshockable to shockable rhythms in out-of-hospital cardiac arrest. Crit Care. 2014; 18(5): 528.

10. Koprivica J., Živanović A. Incidenca vanbolničkog srčanog zastoja u Zrenjaninu. Journal Resuscitatio Balcanica 2018; 9: 89-93.

11. Jakšić H.K, Budimski M, Holcer V.S. et. al. "Eureca One" 2014-Vojvodina. Medicina danas 2015;14(79):108-114.

12. Wallace SK, Abella BS, Shofer FS. et. al. Effect of time of day on prehospital care and outcomes after out-of-hospital cardiac arrest. Circulation. 2013 Apr 16;127(15):1591-6. 